\title{
Kardamom und Schwarzkümmel
}

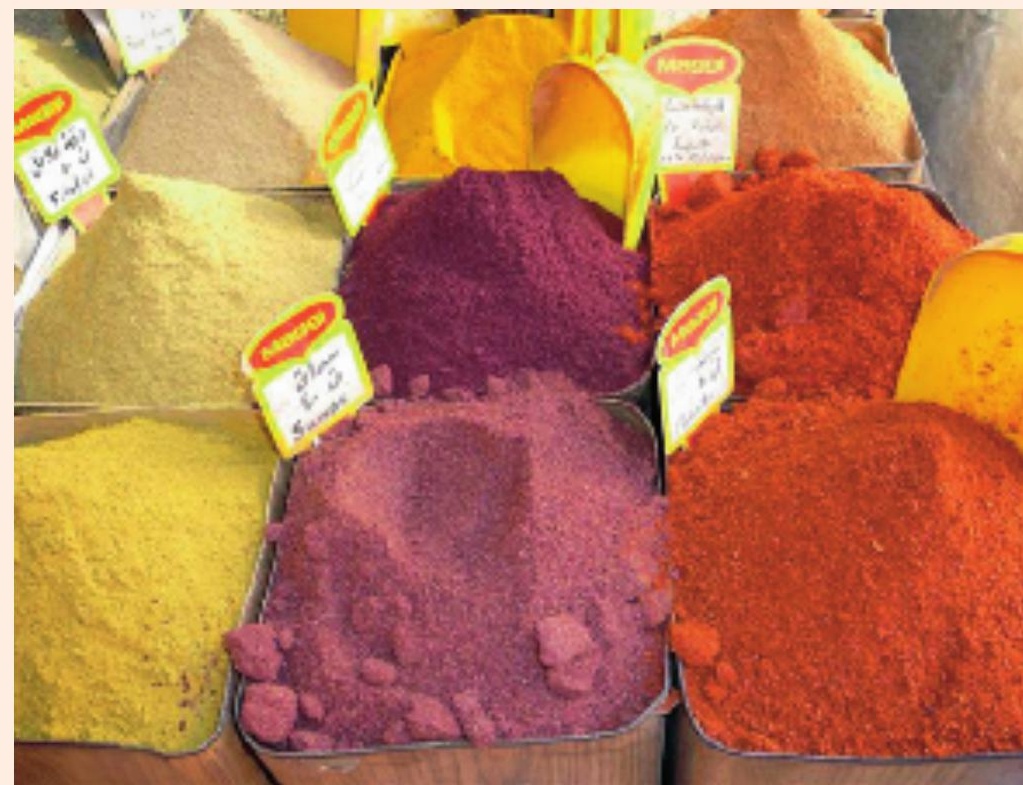

Erhard Taverna

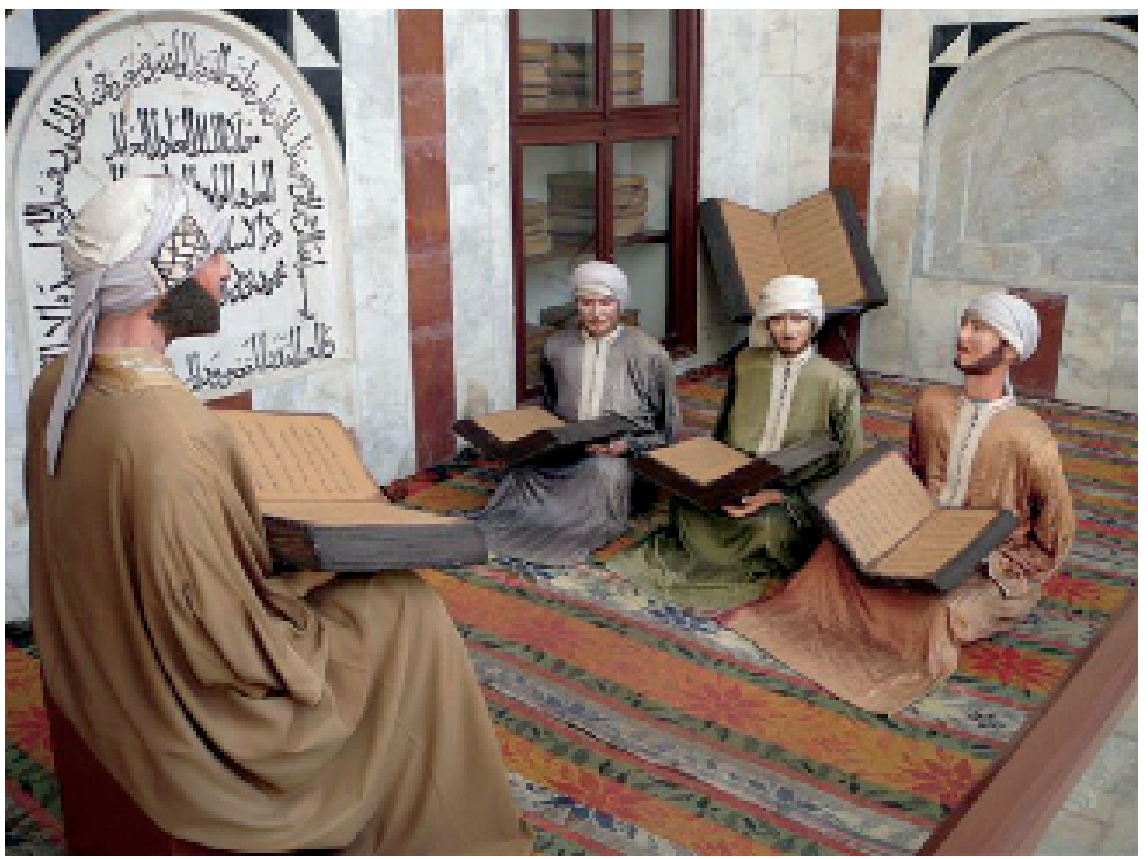

und Spatzen tschilpen auf rostigen Parabolantennen und Wassertanks. Bunte Wäsche hängt in diesem Eldorado aus bröckelnden Kaminen und vergammelndem Plunder.

Der nahe Suq al-Hamidiye, ein Gewirr von überdachten und offenen Strassen, zwischen Umayyaden-Moschee und Zitadelle befriedigt alle Sinne. Im 18. Jahrhundert von einem osmanischen Gouverneur erbaut, ragen neben dem Saftstand noch römische Säulen in den blassblauen Novemberhimmel. Drei junge Männer schuften, um die zahlreiche Kundschaft zu befriedigen. Sie pressen unermüdlich Granatäpfel, Orangen und Äpfel von Hand, leckere Zugaben aus der reichhaltigen syrischen Landwirtschaft. Gegenüber hängen silbrige und goldene Staniolgirlanden, Glühbirnenranken und Weihnachtsschmuck der üppigsten Sorte. Damaszener kaufen ein, Einwohner der wuchernden Vorstädte, Zugereiste aus der ganzen Region, weissgewandete Golfbewohner, schwarzverhüllte Schiiten, Levantiner aller Schattierungen. Wo Saulus zum Paulus wurde, locken Berge von Süssigkeiten, Bonbonhalden, Pistazienkuchen, schokoladeglänzende Festtorten und unbekannte Yoghurtkreationen. Geschmaust und geschleckt wird an jeder Ecke. Propellergetriebene Kinderballone fahren fauchend aus der Menge, Teenies in hautengen Jeans löffeln ein Eis oder knabbern Falafel. In grossen offenen Kesseln kochen Maiskolben, ein Mann hat ein riesiges Messinggefäss geschultert, aus dem er Tee anbietet. Die Auslagen sind mit Gemüse und Früchten vollgestopft. Gewürzberge locken mit Farben und Düften, es riecht nach Schwarzkümmel und Safran, nach Curry 
und Thymian. Die ätherischen Öle des Kardamoms und die Samen vom Schwarzkümmel fördern die dringend erwünschte Magensekretion. Wer zusätzliche medizinische Hilfe braucht, kann sich aus vielen Honigtöpfen eine eigene Mischung herstellen oder aus Reptilienhäuten und Kräutern nach traditioneller Rezeptur ein Heilmittel abwägen lassen. Auf einer Kreuzung liegt der Haupteingang zum früheren al-NûriKrankenhaus, heute Museum der Medizin- und Wissenschaftsgeschichte. Durch das Portal unter dem reichverzierten Türsturz schritten die berühmtesten Ärzte des 12. Jahrhunderts in den Innenhof mit dem damals für Spitäler typischen Wasserbecken, unter ihnen auch Ibn-al-Nafîs, der 300 Jahre vor Harvey den Blutkreislauf der Lungen beschrieb. Der Hof wird auf drei Seiten durch den îwân, einen überwölbten Raum, begrenzt, wo die Schüler unterrichtet wurden. Kostbare Handschriften aus mehreren Jahrhunderten erinnern an die zahlreichen Papiermanufakturen und Übersetzerschulen, die das antike
Erbe überlieferten und weiterentwickelten. Apothekertöpfe, Phiolen, Destillierkolben, Gewürzteller und Mörser belegen eine hochentwickelte Pharmazie und Botanik. Chirurgische Instrumente und ein Narkoseschwamm zeugen vom fortgeschrittenen Handwerk der islamischen Kollegen. Ein Reisender jener Zeit beschrieb das tägliche Treiben: «Morgens früh besuchen die Ärzte die Kranken. Sie verschreiben Medikamente und eine Diät und für die Geisteskranken die nötige Behandlung. Sie behandeln mit Musik und lassen Erzähler und Sänger kommen, um die Kranken ihr Leiden vergessen zu lassen. Nach der Heilung erhalten die Genesenden Kleider und fünf Goldmünzen für die Dauer der Rekonvaleszenz.»

Den Leserinnen und Lesern der Schweizerischen Ärztezeitung wünsche ich im neuen Jahr die Gelehrsamkeit ihrer Vorgänger, eine robuste Verdauung, offene Sinne und ab und zu ein angenehm reinigendes Bad im Hammam. 